\title{
WEIGHTED ESTIMATES FOR BILINEAR FRACTIONAL INTEGRAL OPERATOR OF ITERATED PRODUCT COMMUTATORS ON MORREY SPACES
}

\author{
Xiang Li, Qianjun He* AND DUNYAn Yan
}

Abstract. In this paper we prove several weighted estimates for iterated product commutators generated by $\mathrm{BMO}$-functions and the bilinear fractional integral operators on Morrey spaces. As a corollary we obtain new weighted estimates for Adams type inequality.

Mathematics subject classification (2010): 26A33, 42B25, 42B35.

Keywords and phrases: Iterated product commutator, bilinear fractional integral operator, Morrey space, BMO space, two weight.

\section{REFERENCES}

[1] S. Chanillo, A note on commutators, Indiana Univ. Math. J. 31 (1982), no. 1, 7-16.

[2] R. R. COIFMAn, R. Rochberg AND G. WeIss, Factorization theorems for Hardy spaces in several variables, Ann. of Math. (2) 103 (1976), no. 3, 611-635.

[3] T. IIDA, Weighted inequalities on Morrey spaces for linear and multilinear fractional integrals with homogeneous kernels, Taiwanese J. Math. 18 (2014), no. 1, 147-185.

[4] T. IIDA, Weighted estimates of higher order commutators generated by BMO-functions and the fractional integral operator on Morrey spaces, J. Inequal. Appl. 2016, Paper No. 4, 23 pp.

[5] T. IIDA, E. SATO, Y. SAWANo AND H. TANAKA, Weighted norm inequalities for multilinear fractional operators on Morrey spaces, Studia Math. 205 (2011), no. 2, 139-170.

[6] F. John And L. NiRenberg, On functions of bounded mean oscillation, Comn. Pure Appl. Math. 14 (1961), 415-426.

[7] B. MucKenhoupt And R. L. WheEden, Weighted norm inequalities for fractional integrals, Trans. Amer. Math. Soc. 192 (1974), 261-274.

[8] C. PÉREZ, Two weighted inequalities for potential and fractional type maximal operators, Indiana Univ. Math. J. 43 (1994), no. 2, 663-683.

[9] C. PÉREZ, On sufficient conditions for the boundedness of the Hardy-Littlewood maximal operator between $L^{p}$ spaces with different weights, Proc. London Math. Soc. (3) 71 (1995), no. 1, 135-157.

[10] C. PÉrez, Sharp $L^{p}$-weighted Sobolev inequalities, Ann. Inst. Fourier (Grenoble) 45 (1995), no. 3, 809-824.

[11] C. PÉREZ AND ISRAel P. Rivera-Rios, Borderline weighted estimates for commutators of singular integrals, Israel J. Math. 217 (2017), no. 1, 435-475.

[12] Y. SaWANO, S. SUgANO AND H. TANAKA, Generalized fractional integral operators and fractional maximal operators in the framework of Morrey spaces, Trans. Amer. Math. Soc., 363 (2011), no. 12, 6481-6503.

[13] H. TANaKa, Morrey space and fractional operators, J. Aust. Math. Soc. 88 (2010), no. 2, 247-259. 